University of Nebraska - Lincoln

DigitalCommons@University of Nebraska - Lincoln

Faculty Papers and Publications in Animal

Science

Animal Science Department

1991

\title{
Distribution of Time to First Postpartum Estrus in Beef Cattle
}

S. M. Azzam

University of Nebraska-Lincoln

L. A. Werth

University of Nebraska-Lincoln

J. E. Kinder

University of Nebraska-Lincoln, kinder.15@osu.edu

Merlyn K. Nielsen

University of Nebraska-Lincoln, mnielsen1@unl.edu

Follow this and additional works at: https://digitalcommons.unl.edu/animalscifacpub

Part of the Animal Sciences Commons

Azzam, S. M.; Werth, L. A.; Kinder, J. E.; and Nielsen, Merlyn K., "Distribution of Time to First Postpartum Estrus in Beef Cattle" (1991). Faculty Papers and Publications in Animal Science. 487.

https://digitalcommons.unl.edu/animalscifacpub/487

This Article is brought to you for free and open access by the Animal Science Department at DigitalCommons@University of Nebraska - Lincoln. It has been accepted for inclusion in Faculty Papers and Publications in Animal Science by an authorized administrator of DigitalCommons@University of Nebraska - Lincoln. 


\title{
DISTRIBUTION OF TIME TO FIRST POSTPARTUM ESTRUS IN BEEF CATTLE1
}

\author{
S. M. Azzam, L. A. Werth, J. E. Kinder and M. K. Nielsen ${ }^{2}$ \\ University of Nebraska, Lincoln 68583-0908
}

\begin{abstract}
The function of a distribution that describes postpartum interval (PPI) under any experimental treatment is useful for simulation modeling, understanding the effects of stimuli on the endocrine system, and estimating the average PPI in experiments terminated before all animals have expressed estrus. This study was undertaken to compare the fit of three statistical distributions, the Weibull, the log-normal, and the linear hazard rate (LHR), to the empirical distribution of PPI for five treatment regimens: no bull exposure postpartum, bull exposure from $53 \mathrm{~d}$ postpartum, bull exposure from $3 \mathrm{~d}$ postpartum, and bull exposure from an average of $63 \mathrm{~d}$ postpartum for 2 -yr-old cows and for mature cows. The Weibull and the log-normal distributions deviated considerably from the empirical distribution. The LHR distribution with parameters changing over three different regions gave an excellent fit. The resulting hazard rate (instantaneous probability of a cow expressing her first estrus at time $t$ postpartum) revealed a low probability of expressing estrus within $27 \mathrm{~d}$ postpartum (43 d for 2 -yr-olds). For cows not exposed to bulls, the hazard rate increased slowly with time. For cows exposed to bulls after $3 \mathrm{~d}$ postpartum, the hazard rate increased rapidly between $\mathrm{d} 27$ and $\mathrm{d}$ 50. For cows exposed to bulls after $53 \mathrm{~d}$ postpartum, the hazard rate increased instantaneously approximately $12 \mathrm{~d}$ after initial exposure to bulls. This increase was also seen when cows were exposed to bulls beginning at a constant date (at an average of $63 \mathrm{~d}$ postpartum). Because of lack of fit, the Weibull and the log-normal distributions should not be used in survival analysis of PPI. The LHR distribution with parameters changing over three different regions does not lend itself to survival analysis methods.
\end{abstract}

Key Words: Postpartum Interval, Beef Cows, Bulls, Exposure, Stochastic Models

J. Anim. Sci. 1991. 69:2563-2570

\section{Introduction}

Frequency diagrams of time to first postpartum estrus (PPI) in cows reveal that PPI may not be normally distributed (Figure 1). When cows are not exposed to bulls until all cows have resumed estrous cycles (Figure 1b), the distribution is slightly skewed, but a test of normality failed to reject the hypothesis that PPI is normally distributed. Under different

\footnotetext{
${ }^{1}$ Published as Paper No. 9123, Journal Series, Nebraska Agric. Res. Div., Lincoln. This research was supported by USDA grant 85-CRSR-2-2546.

2 Anim. Sci. Dept., Univ. of Nebraska, Lincoln.

Received February 5, 1990.

Accepted January 9, 1991.
}

treatments, such as exposing cows to bulls at certain times after parturition, the distribution of PPI becomes distinctly skewed (Figure 1, a and c). Finding a single statistical distribution that adequately describes PPI under any treatment would be useful in 1) stimulation modeling, 2) understanding the effects of treatment stimuli on the endocrine system in postpartum cows, and 3) estimating, by survival analysis, the average PPI in experiments that have been terminated before all animals have had an estrus.

The primary objective of this study was to compare the fit and usefulness of three statistical distributions to the empirical PPI for five treatment regimens: no bull exposure postpartum, bull exposure from $53 \mathrm{~d}$ postpar- 


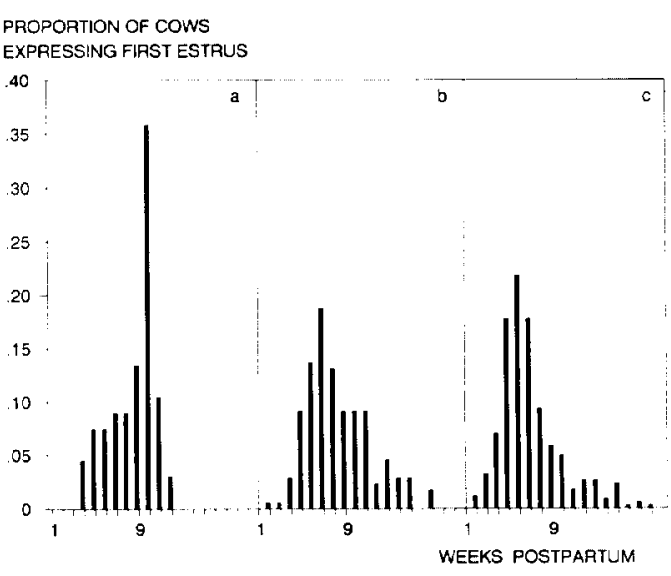

Figure 1. Histogram of postpartum intervals for (a) cows exposed to bulls from $53 \mathrm{~d}$ postpartum, (b) cows not exposed to bulls, and (c) cows exposed to bulls from $3 \mathrm{~d}$ postpartum.

tum, bull exposure from $3 \mathrm{~d}$ postpartum, and bull exposure from a constant date (an average of $63 \mathrm{~d}$ postpartum) for 2-yr-old and mature cows. A secondary objective was to use the best fitting statistical distribution to analyze how bull exposure affects the rate at which cows resume estrous cycles.

\section{Materials and Methods}

Data. Five sets of data collected in eastern Nebraska were used in the study. The first three sets of data were collected in 1981 to 1982 and 1985 to 1988 . The PPI was measured as the time from parturition to development of first luteal tissue as determined by progesterone concentrations obtained from once-weekly blood samples (Zalesky et al., 1984). The first set of data (67 records from 1981 and 1982) came from cows that were not exposed to bulls immediately after parturition. At $53 \mathrm{~d}$ postpartum, the cows were moved to a herd with bulls (Figure 1a). Cows contributing to the second set of data (176 records from 1985 to 1988) were never exposed to bulls (Figure 1b). The third set of data (344 records from 1981, 1982, and 1985 to 1988 ) came from cows exposed to bulls from $3 \mathrm{~d}$ postpartum. Other treatments (age of bull, age of cow, and feed energy level) were superimposed on the study in some years, but we ignored those treatments in this study because of the small number of animals in a single year by treatment combination. The effect of bull exposure on resumption of estrous cycles for 2 yr of these data (1981 and 1982) was reported by Zalesky et al. (1984).

The last two sets of data consisted of 176 records (1980 to 1983) of PPI from 2-yr-old cows and 479 records (1981 to 1985) of PPI from mature cows, respectively. Management of the cows has been described by Clutter and Nielsen (1987) and MontañoBermudez and Nielsen (1990). Cows were not exposed to bulls until the beginning of the breeding season on May 31 of each year. This date corresponds to an average postpartum interval of $63 \mathrm{~d}$ for both 2-yr-old and mature cows. The PPI was measured as time from parturition to first estrus, as determined by observation of estrous behavior.

Five days were deducted from PPI in the first three sets of data to adjust all dates to a behavioral estrous date (PPI as determined from blood assay was found to occur on the average $5 \mathrm{~d}$ after PPI as determined by estrous behavior). In the statistical analysis, PPI was coded so that the earliest PPI occurred on $\mathrm{d} 1$. Because no cows had a PPI of less than $10 \mathrm{~d}$, this amounted to deducting $9 \mathrm{~d}$ from PPI in all sets of data.

Statistical Methods. Methods used are described in detail by Lawless (1982). To aid in finding a suitable distribution, we hypothesized that the hazard rate (the instantaneous probability of a cow expressing her first postpartum estrus at time $t$ ) would increase with time. Three distributions were considered in the study: the Weibull, log-normal, and linear hazard rate (LHR) distributions. The Weibull was chosen because it has been widely used to describe time-dependent events, has an increasing hazard rate, and is included in statistical software for survival analysis (SAS, 1985). It has been used to describe differences in age at puberty and survival in cattle (Azzam et al., 1986; Pennel et al., 1986; Rohrer et al., 1988; Wolfe et al., 1990). The log-normal is also widely used and is included in survival analysis software; however, the hazard rate only increases initially, and it becomes 0 as time increases. The LHR distribution has an increasing hazard rate but the distribution has not been used as extensively as the Weibull and log-normal distributions. An example of its use was discussed by Gehan and Siddiqui (1973).

The survivor functions $[S(t)]$, that is, the proportions of cows still anestrous at a given 
time postpartum, for the three distributions are as follows:

$$
\begin{aligned}
& S(t)=e^{-(\lambda t)^{\kappa}} \quad \text { (Weibull) } \\
& S(t)=1-\Phi\left(\frac{\log t-\mu_{\log t}}{\sigma \log t}\right)(\log -\text { normal }) \\
& S(t)=\mathrm{e}^{-\left(\alpha_{1} t+\alpha_{2} t^{2}+\cdots+\alpha_{n} t^{n}\right)} \text { (LHR), }
\end{aligned}
$$

where $t$ stands for days postpartum, $\Phi$ stands for the normal cumulative distribution function, $\lambda, \kappa, \mu_{\log t}, \sigma_{\log t}$, and $\alpha_{1} \cdots \alpha_{n}$ are parameters of the distributions, and $n$ is the order of the polynomial. The hazard rates can be found by taking the derivatives of $-\log S(t)$ with respect to $t$.

When PPI has a Weibull distribution, $\log (-\log S(t))=\kappa \log \lambda+\kappa \log t$. The survivor function, $S(t)$, was estimated as the number of observations greater or equal to $t$, divided by the total number of observations. Estimates of parameters were obtained by regressing $\log (-$ $\log \hat{S}(t))$ on $\log t$ and solving for $\kappa$ and $\lambda$.

When PPI has a LHR distribution, $-\log S(t)$ $=\alpha_{1} t+\alpha_{2} t^{2}+\cdots+\alpha_{n} t^{n}$. Dividing both sides of the equation by $t$ gives $(-\log S(t)) / t=\alpha_{1}+$ $\alpha_{2} t+\cdots+\alpha_{N} t^{n-1}$. Estimates of the $n$ parameters were obtained by regressing (-log $\hat{S}(t)) / t$ on $t$.

If PPI is $\log$-normally distributed, then $\log t$ is normally distributed with mean $\mu_{\text {logt }}$ and variance $\sigma_{\log t}^{2}$. The parameters for the log. normal distribution were therefore estimated by the mean and variance of $\log t$.

To estimate parameters for the LHR distribution, data were first plotted. Plotting of $(-\log \hat{S}(t))$ on $t$ revealed that a single polynomial function over the entire range of PPI might not give the best fit. Based on the data, we hypothesized that there are three different regions in which parameters of the distribution are different (Figure 2). The hypothesis can be supported by physiological considerations. Until a certain date postpartum $\left(t_{1}\right)$, the probability of a beef cow exhibiting estrus increases little with time. After $t_{1}$, cows are able to respond to treatment stimuli such as bull exposure, and the probability of a cow's exhibiting estrus increases significantly if the cow is exposed to the treatment. If cows are not exposed to the treatment, the probability of their exhibiting estrus still increases with time. After this period of sensitivity to stimuli $\left(t_{2}\right)$,

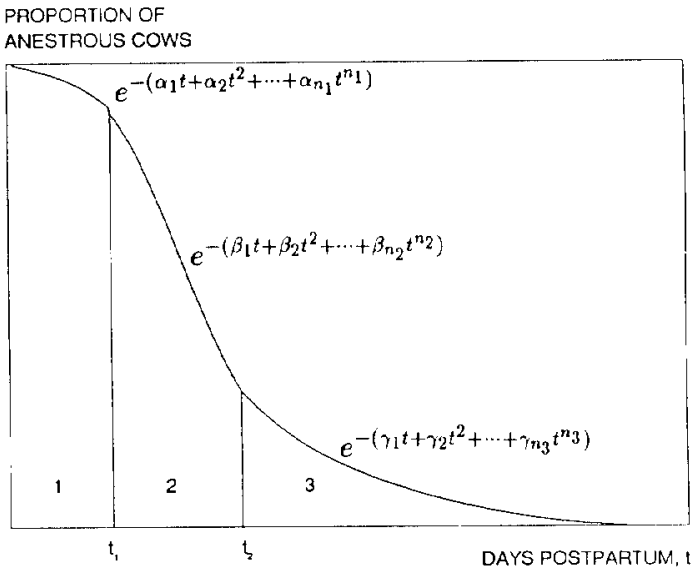

Figure 2. Hypothesized proportion of cows, still anestrous, as a function of days postpartum $(S(t))$. The parameters of the linear hazard rate distribution are different in the three different regions. The three regions are defined by the values $t_{1}$ and $t_{2}$.

the probability of a cow's exhibiting estrus increases with time, but not at the same rate as when the cow responds to a stimulus. However, if cows were not exposed to a stimulus until time $t_{2}$, the probability of their having a postpartum estrus after $t_{2}$ would be expected to increase significantly.

It would be desirable if one could simultaneously find the values of $t_{1}$ and $t_{2}$ and the polynomials in the three regions that would minimize the squared deviations of actual minus predicted proportions, subject to the constraint that the prediction equation has to be nonincreasing within and across regions. In our analysis, $t_{1}$ and $t_{2}$ were first determined by visual inspection of the plot $([-\log \hat{S}(t)] / t$ on $t$. Separate regression equations were then obtained for the three different regions. The degree of the polynomial in each region was determined by the significance of the terms. If, however, the prediction equation

$$
\begin{aligned}
S(t)= & e^{-\left(\alpha_{1} t+\alpha_{2} t^{2}+\cdots+\alpha_{n_{1}} t^{n 1}\right)} \\
& \text { for } t \leq t_{1} \\
S(t)= & e^{-\left(\beta_{1} t+\beta_{2} t^{2}+\cdots+\beta_{n_{2}} t^{n 2}\right)} \\
& \text { for } t_{1}<t \leq t_{2} \\
S(t)= & e^{-\left(\gamma_{1} t+\gamma_{2} t^{2}+\cdots+\gamma_{n_{3}} t^{n 3}\right)} \\
& \text { for } t>t_{2}
\end{aligned}
$$

was found to increase for any values of $t$, a lower-order polynomial was chosen for any 
TABLE 1. ESTIMATED COEFFICIENTS OF THE LINEAR HAZARD RATE DISTRIBUTION

\begin{tabular}{|c|c|c|c|c|c|}
\hline $\begin{array}{l}\text { Data } \\
\text { set }^{\text {a }}\end{array}$ & Region $^{b}$ & Intercept & Linear & Quadratic & Cubic \\
\hline 1 & $t \leq 13$ & 0 & & & \\
\hline 1 & $13<t \leq 56$ & $-.001891 * * *$ & $.00026022 * * *$ & & \\
\hline 1 & $t>56$ & $-.169742 * * *$ & $.00330743 * * *$ & & \\
\hline 2 & $t \leq 18$ & $.001061 \uparrow$ & .00000415 & & \\
\hline 2 & $18<t \leq 41$ & $-.009413 * * *$ & $.00058673 * * *$ & & \\
\hline 2 & $t>41$ & $-.003082^{* * *}$ & $.00043460^{* * *}$ & & \\
\hline 3 & $t \leq 18$ & $.002890^{* * *}$ & -.00004358 & $.0000104022^{* *}$ & \\
\hline 3 & $18<t \leq 41$ & $.014767 \dagger$ & $-.00188178^{*}$ & $.0000960942 * *$ & $-.000001003380^{* *}$ \\
\hline 3 & $t>50$ & -.014086 & $.00202708 * * *$ & $-.0000295083^{* * *}$ & $.000000153146^{* * *}$ \\
\hline 4 & $t \leq 34$ & $.002542^{* * *}$ & $.00002472 * *$ & & \\
\hline 4 & $34<t \leq 77$ & $-.044991 * * *$ & $.00283267^{* * *}$ & $-.0000535554 * * *$ & $.000000356005^{* * *}$ \\
\hline 4 & $t>77$ & $-.103392 * * *$ & $.00158108 * * *$ & & \\
\hline 5 & $t \leq 18$ & $.004059 * * *$ & $-.00045308 * *$ & $.0000189631 *$ & \\
\hline 5 & $18<t \leq 61$ & $-.005161 * *$ & $.00055641 * * *$ & $-.0000077367^{*}$ & $.000000084985^{* *}$ \\
\hline 5 & $t>61$ & $-.045691 * * *$ & $.00108976^{* * *}$ & & \\
\hline
\end{tabular}

${ }^{a} 1$ : Cows exposed to bulls after $53 \mathrm{~d}$ postpartum; 2: cows not exposed to bulls; 3 : cows exposed to bulls $3 \mathrm{~d}$ after parturition; 4: 2-yr-old cows exposed to bulls after an average of $63 \mathrm{~d}$ postpartum; 5: mature cows exposed to bulls after an average of $63 \mathrm{~d}$ postpartum.

b The analysis was done on $t$ defined as the actual postpartum interval minus $9 \mathrm{~d}$. Thus, the limits of $t$ are in days postpartum minus 9.

$\dagger P<.10$.

$* P<.05$.

$* * P<.01$.

$* * * P<.001$.

one region until the necessary condition was satisfied.

To determine which distribution gave the best fit one would have to compare the sums of squares of the residuals. However, because parameters were estimated differently for the three distributions and the residuals may not be normally and independently distributed with a common variance, a nonparameteric goodnessof-fit test was performed. For each set of data, the hypothesis that the observed data came from either the Weibull, log-normal, or LHR distribution was tested by the KolmogorovSmimov test for an intrinsic (= parameters are estimated from the data) hypothesis. If the hypothesis was not rejected for either one of the three distributions for a particular set of data, we can only conclude that the data could have come from any of the three distributions. We cannot distinguish which distribution gave the best fit.

\section{Results}

The estimated coefficients of the LHR distribution are given in Table 1. The term "LHR distribution" might be misleading be- cause, with three different regions, the resulting distribution is actually a mixture of a continuous and a discrete distribution. For the sake of simplicity, however, we will continue to refer to it as the LHR distribution. The regression equations are presented graphically in Figure 3 for the first three sets of data and in Figure 4 for the last two sets of data. The resulting prediction equation of proportion still anestrous $(S(t))$ for the first three sets of data are presented in Figure 5.

On examining the closeness of fit of the three distributions (LHR, Weibull, and lognormal), it was evident from the KolmogorovSmirnov $D$-statistic that the LHR distribution fit the data extremely well but that the predicted proportions from the two other distributions deviated considerably from the empirical proportions when cows were exposed to bulls postpartum (Table 2). The hypothesis that the data have an LHR distribution with parameters switching at three different times postpartum could not be rejected by the Kolmogorov-Smimov goodness-of-fit test for any set of data. The hypothesis that the data came from either a Weibull or a lognormal distribution was rejected when cows 


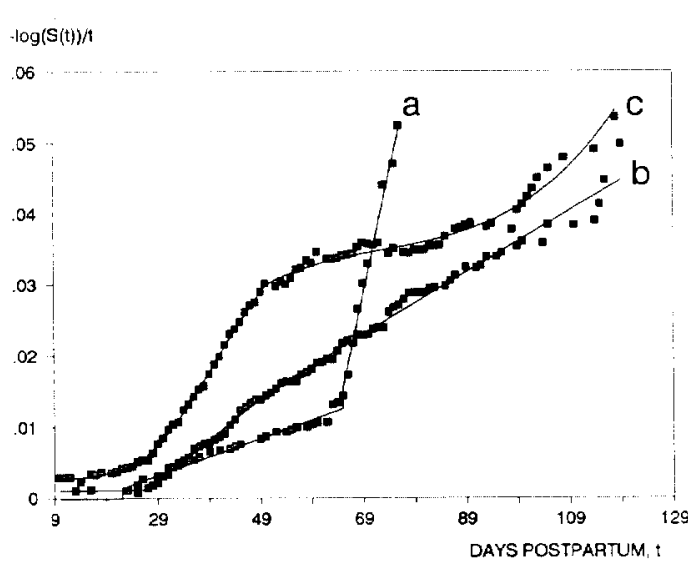

Figure 3. Observed (D) and predicted values (based on the linear hazard rate distribution) for $(-\log \hat{S}(t)) / t$, where $t$ is day postpartum. (a) Cows exposed to bulls from $53 \mathrm{~d}$ postpartum, (b) cows not exposed to bulls, (c) cows exposed to bulls from 3 d postpartum.

were exposed to bulls (Table 2; data sets 1,3 , 4 , and 5). The fits of the Weibull and the lognormal distributions are shown graphically for the third set of data (bull exposure from $3 \mathrm{~d}$ postpartum) in Figure 6. Both distributions underestimated the proportion of cows still anestrous for low values of PPI and overestimated the proportions for medium values of PPI.

The hazard rate for the LHR distribution is $\alpha_{1}+2 \alpha_{2} t+\cdots+n \alpha_{n} t^{n-1}$ for $t \leq t_{1}, \beta_{1}+$ $2 \beta_{2} t+\cdots+n \beta_{n} t^{n-1}$ for $t_{1}<t \leq t_{2}$, and $\gamma_{1}+$ $2 \gamma_{2} t+\cdots+n \gamma_{n} t^{n-1}$ for $t>t_{2}$. Predicted hazard rates, using estimates of the parameters (Table 1), are shown in Figures 7 and 8 . In the first three sets of data, there was little or no increase regardless of treatment until $d 27$ postpartum. Between d 27 and 50 (23-d duration), cows exposed to bulls had a more rapid increase in the probability of expressing estrus than cows not exposed to bulls. However, after $50 \mathrm{~d}$ the group of cows exposed to bulls from $\mathrm{d} 3$ and the group without exposure to bulls had similar, increasing rates. The effect of exposing cows to bulls from d 53 postpartum was not seen until after $d 65$. At this time the hazard rate increased instantaneously to almost .20 , followed by a rapid increase.

In the two groups in which bulls were added to the cow herd at a fixed date (Figure 8) there was a considerable difference between the 2-yr-old and mature cows. Hazard rates for

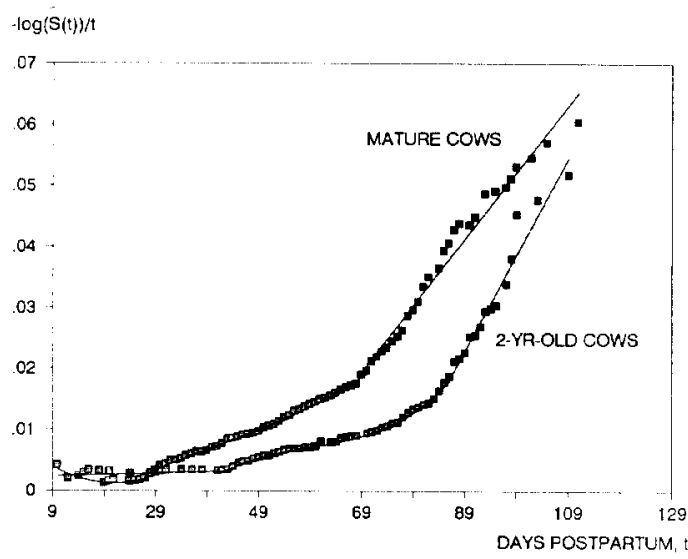

Figure 4. Observed (D) and predicted values (based on the linear hazard rate distribution) for $(-\log \hat{S}(t)) / t$, where $t$ is day postpartum. Mature and 2-yr-old cows were exposed to bulls from an average of $63 \mathrm{~d}$ postpartum.

the two groups were similar in each of the regions but the 2-yr-old cows were delayed on the average by $16 \mathrm{~d}$ in initiation of estrous cycles and in their response to bull stimulus ( $t_{1}$ and $t_{2}$ for the 2-yr-old cows occurred $16 \mathrm{~d}$ after those for the mature cows). Initially there was little or no increase in the probability of expressing estrus (until d 27 and 43 in mature and 2-yr-old cows, respectively). During the following $43 \mathrm{~d}$ (approximately the length of

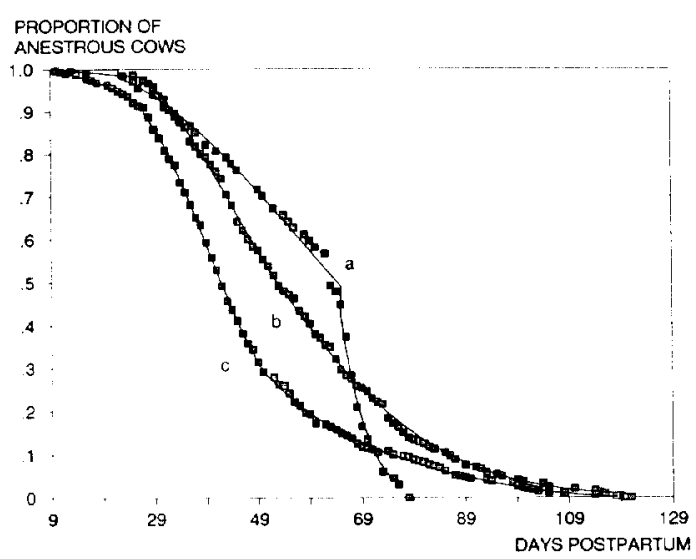

Figure 5. Observed ( $)$ and predicted values (based on the linear hazard rate distribution) for $S(t)$ (proportion of cows, anestrous at time $t$ ), where $t$ is day postpartum. (a) Cows exposed to bulls from $53 \mathrm{~d}$ postpartum, (b) cows not exposed to bulls, and (c) cows exposed to bulls from $3 \mathrm{~d}$ postpartum. 
PROPORTION OF

ANESTROUS COWS

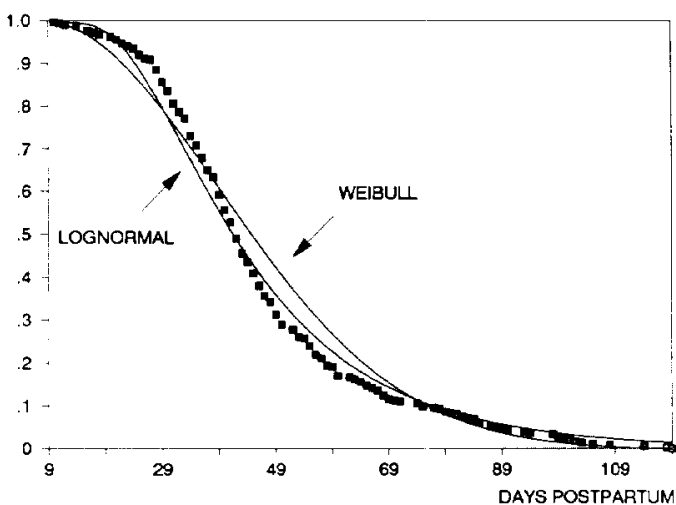

Figure 6. Observed $(\square)$ and predicted values for $S(t)$ (proportion of cows, anestrous at time $t$ ), where $t$ is day postpartum. Predictions are based on the Weibull and lognormal distributions for cows exposed to bulls from $3 \mathrm{~d}$ postpartum.

two estrous cycles) the probability increased with the more rapid increase in 2-yr-olds. Thereafter, there was a sudden increase in the hazard rate, probably reflecting the effect of bull exposure.

\section{Discussion}

Analysis of the distributions for initiation of estrous cycles after parturition in beef cows has important physiological implications. During the first 4 wk postpartum, most beef cows

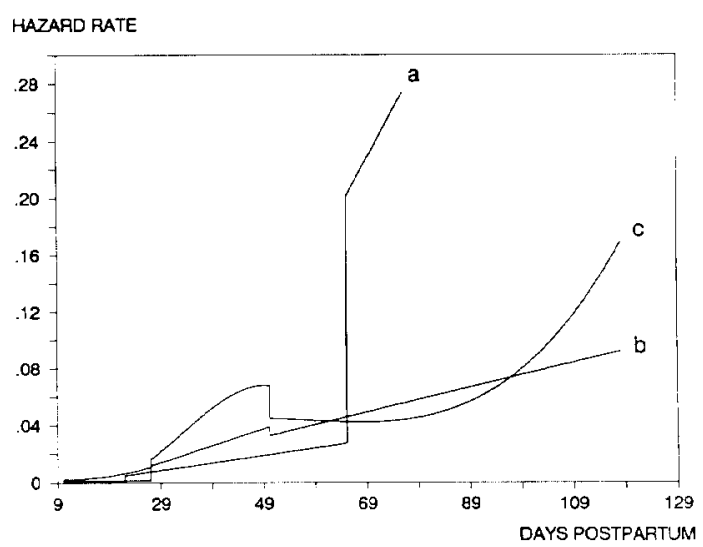

Figure 7. Hazard rate (instantaneous probability of expressing estrus at time $t$ postpartum, given that the cow has been anestrous until time $t$ ) based on linear hazard rate distribution. (a) Cows exposed to bulls from $53 \mathrm{~d}$ postpartum, (b) cows not exposed to bulls, and (c) cows exposed to bulls from 3 d postpartum.

are not capable of exhibiting estrous cycles regardless of whether bulls are present or not. After 4 wk postpartum, some cows are capable of responding to bulls by shortening their PPI. This is evident from the increased hazard rate during the following 3 wk relative to cows that were not exposed to bulls. However, after 7 wk of bull exposure, the hazard rate in the cows still exposed to bulls did not seem to differ from that in cows that had not been exposed to bulls. This could be interpreted to

TABLE 2. KOLMOGOROV-SMIRNOV GOODNESS OF FIT TEST

\begin{tabular}{|c|c|c|c|c|c|}
\hline \multirow{2}{*}{$\begin{array}{l}\text { Data } \\
\text { set }^{\mathrm{a}}\end{array}$} & \multirow[b]{2}{*}{$\mathrm{n}^{\mathbf{b}}$} & \multicolumn{3}{|c|}{ Kolmogorov-Smirnov D-statistic } & \multirow[b]{2}{*}{ Critical value $^{\mathrm{d}}$} \\
\hline & & Weibull & Log-normal & LHR $^{c}$ & \\
\hline 1 & 37 & .19 & 23 & $.10^{e}$ & .12 \\
\hline 2 & 79 & $.06^{e}$ & $.07^{e}$ & $.04^{e}$ & .08 \\
\hline 3 & 85 & .12 & .09 & $.05^{\mathrm{e}}$ & .08 \\
\hline 4 & 73 & .20 & .17 & $.04^{e}$ & .09 \\
\hline 5 & 80 & .10 & .11 & $.04^{e}$ & .08 \\
\hline
\end{tabular}

$a_{1}$ : Cows exposed to bulls after 53 d postpartum; 2: cows not exposed to bulls; 3 : cows exposed to bulls after $3 \mathrm{~d}$ postpartum; 4: 2-yr-old cows exposed to bulls after an average of $63 \mathrm{~d}$ postpartum; 5 : mature cows exposed to bulls after an average of $63 \mathrm{~d}$ postpartum.

bumber of deviations in the data set (number of distinct values of $t$ ).

cLinear hazard rate.

${ }^{\mathrm{d}}$ The critical value of the one-sample Kolmogorov-Smimov statistic for an intrinsic hypothesis is $.736 / \sqrt{n}$ (Rohlf and Sokal, 1981).

The hypothesis that the observed data came from the given distribution cannot be rejected ( $D$-statistic is less than the critical value). 
HAZARD RATE

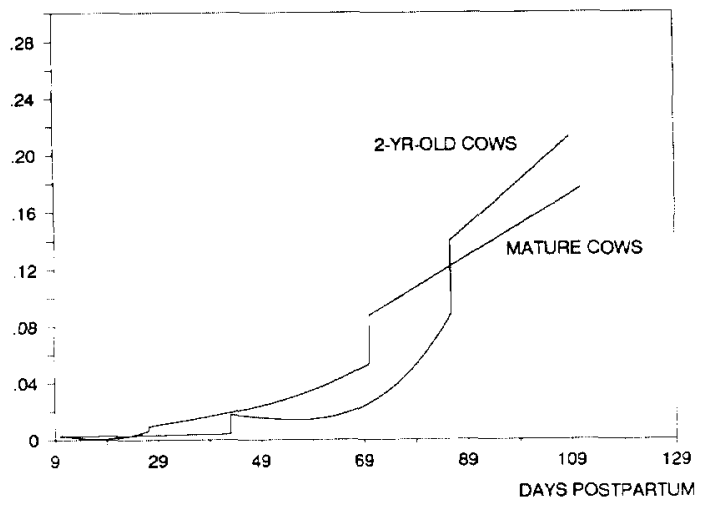

Figure 8. Hazard rates (based on the linear hazard rate distribution) for mature and 2-yr-old cows exposed to bulls from an average of $63 \mathrm{~d}$ postpartum.

indicate that not all cows that receive male stimulus immediately after parturition are able to respond by shortening their PPI. When bull stimulus is postponed until 8 to 9 wk postpartum, more animals seem to be able to respond to the stimulus, as indicated by a instantaneous increase in the hazard rate, followed by a continuing linear increase.

The delay from time of bull exposure to initiation of estrous cycles is an interesting observation. It is assumed that the signal from the male to the female that influences onset of estrous cycles is pheromonal. This assumption is based on a study by Izard and Vandenbergh (1982), in which they concluded that there is a pheromone in bull urine that hastens the onset of puberty in heifers. Signals of this nature indirectly influence, via the nervous system, the hypothalamo-pituitary axis to enhance secretion of the gonadotropins from the anterior pituitary. The increased gonadotropic secretion would act on the ovary to stimulate follicle development and estrogen synthesis to the point that behavioral estrus occurs. Obviously, any effect on estrual behavior of an exogenous stimulus that acts through the endocrine and physiological axes would take time. Therefore, we speculate that the delay from exposure of females to males until the influence is detected on behavioral reproductive functions is due to the sequential activation of the endocrine and physiological processes necessary for expression of behavioral estrus.
One of the objectives of the study was to find a distribution that could be used in survival analysis to estimate the mean PPI in experiments that have been terminated before all animals have had a postpartum estrus. Because the Weibull and log-normal distributions did not fit the data well (Table 2), survival analysis using these two distributions for prediction of PPI is not recommended in bull-exposure studies. The LHR, using three different regions, fit the data well. However, because PPI is now considered to have continuous and discrete properties, the distribution does not lend itself to survival analysis. Problems with survival analysis based on this type of distribution are obvious. For example, if censoring (termination of the experiment) occurred before $t_{2}$, no data would be available to estimate the parameters for $S(t)$ in the last period. It is possible that another distribution could be found that would fit the data well and also be easy to work with. The hazard rates presented should aid in finding such a distribution.

For use in simulation models, the LHR distribution is recommended over the Weibull and log-normal distributions in modeling PPI. However, if parameters of the Weibull distribution had been allowed to change over different periods of PPI, as was allowed for the LHR distribution, the Weibull distribution may also have fit the data well. The plot of $\log (-\log S(t))$ on $\log (t)$, if parameters were allowed to change over different periods, should consist of a series of linear functions. When $\log (-\log \hat{S}(t))$ was plotted against $\log (t)$ for the five sets of data, the plots were not linear over large enough ranges of PPI. Therefore, estimation of parameters for the Weibull distributions for different periods of PPI was not pursued. Because simple plotting and regression procedures were not used for the log-normal distribution, changing the parameters of the log-normal distribution over different periods of PPI was also not pursued.

Stochastic simulation of PPI has been reported by Oltenacu et al. (1980) and Johnson and Notter (1987). Oltenacu et al. (1980) modeled days to first ovulation in dairy cattle by a gamma distribution, truncated to include only animals with values between 10 and $80 \mathrm{~d}$ (20 to $100 \mathrm{~d}$ if "reproductively abnormal"). Johnson and Notter (1987) modeled postpartum anestrous interval by adding three random variables; the additive genetic and permanent 
environmental effects were assumed to be normally distributed, and the temporary environmental effect was assumed to have a Pearson III gamma distribution. Predicted PPI using these distributions have not been compared to actual data. Algorithms using the functions in Table 1 have been included to generate PPI in a model that simulates reproductive management systems in beef cattle (Azzam et al., 1990).

\section{Implications}

When cows are exposed to bulls postpartum, neither the Weibull nor the log-normal distribution fit the data. The use of these distributions in survival analysis of postpartum interval is therefore not recommended in bullexposure studies. For simulation modeling, the linear hazard rate distribution, with parameters switching over three different regions, fit the data under any treatment. Exposing cows to bulls postpartum decreases postpartum interval. This study shows that the rate with which cows respond to bull exposure (proportion of cows responding and time to response) differs with beginning time of exposure (number of days postpartum) and with age of cow.

\section{LIterature Cited}

Azzam, S. M., J. E. Kinder and M. K. Nielsen. 1990. Modelling reproductive management systems for beef cattle. Agric. Systems 34:103.

Azzam, S. M., P. L. Pennel, J. E. Kinder, D. R. Zimmerman and M. K. Nielsen. 1986. Estimation of expected time to puberty in terminated experiments using survival analysis. J. Anim. Sci. 63(Suppl. 1):129 (Abstr.).

Clutter, A. C. and M. K. Nielsen. 1987. Effect of level of beef cow milk production on pre- and postweaning calf growth. J. Anim. Sci. 64:1313.

Gehan, E. A. and M. M. Siddiqui. 1973. Simple regression methods for survival time studies. J. Am. Stat. Assoc. 68:848.

Izard, M. K. and J. G. Vandenbergh. 1982. The effects of bull urine on puberty and calving data in crossbred beef heifers. J. Anim. Sci. 55:1160.

Johnson, M. H. and D. R. Notter. 1987. Simulation of genetic control of reproduction in beef cows. I. Simulation model. J. Anim. Sci. 65:68.

Lawless, J. F. 1982. Statistical Models and Methods for Lifetime Data. John Wiley \& Sons, New York

Montaño-Bermudez, M. and M. K. Nielsen. 1990. Reproductive performance and variation in body weight during annual cycles for crossbred beef cows with different genetic potential for milk. J. Anim. Sci. 68: 2289.

Oltenacu, P. A., R. A. Milligan, T. R. Rounsaville and R. H. Foote. 1980. Modelling reproduction in a herd of dairy cattle. Agric. Systems 5:193.

Pennel, P. L., D. D. Zalesky, M. L. Day, M. W. Wolfe, T. T. Stumpf, S. M. Azzam, R. J. Kittok and J. E. Kinder. 1986. Influence of bull exposure on initiation of estrous cycles in prepubertal beef heifers. J. Anim. Sci. 63(Suppl. 1):129 (Abstr.).

Rohlf, F. J. and R. R. Sokal. 1981. Statistical Tables (2nd Ed.). W. H. Freeman and Co., San Francisco, CA.

Rohrer, G. A., J. F. Baker, C. R. Long and T. C. Cartwright. 1988. Productive longevity of first-cross cows produced in a five-breed diallel: I. Reasons for removal. J. Anim. Sci. 66:2826.

SAS. 1982. SAS User's Guide: Statistics. SAS Inst., Inc., Cary, NC.

Wolfe, M. W., T. T. Stumpf, P. L. Wolfe, M. L. Day, R. M. Koch and J.E. Kinder. 1990. The effect of selection for growth traits on age and weight at puberty in bovine females. J. Anim. Sci. 68:1595.

Zalesky, D. D., M. L. Day, M. Garcia-Winder, K. Imakawa, R. J. Kittok, M. J. D'Occhio and J. E. Kinder. 1984. Influence of exposure to bulls on resumption of estrous cycles following parturition in beef cows. J. Anim. Sci. 59:1135. 